\title{
Editorial
}

\section{Methane production: Where should we focus our attention?}

The UN recently called for reducing meat consumption due to its contribution to global warming. However, from my perspective as a researcher, the role of livestock greenhouse gas emissions is often exaggerated.

The annual reports of greenhouse gas (GHG) emissions from the $\mathrm{EU}^{1}$ and the $\mathrm{USA}^{2}$ reveal that the contribution of agriculture, particularly the livestock sector, is of little relevance compared to that of other industries. Thus, focusing attention and efforts to decrease emissions in those sectors would have a greater influence on GHG than the reduction of meat consumption.

The May $2019 \mathrm{EU}$ report indicates that 4,330 tons of $\mathrm{CO}_{2}$ equivalent were emitted in 2017 , almost $80 \%$ of which were from the energy industry and only $10 \%$ (440ton) were from agriculture. Of those 440 tons, less than $40 \%$ corresponds to enteric fermentation methane. Furthermore, all GHG producing sectors have decreased their production of $\mathrm{CO}_{2}$ equivalent since 1990, except for transportation and air conditioning, which together have increased by more than 260 tons in the same period. The equivalent $\mathrm{CO} 2$ production of cattle in Europe was 190 tons and has decreased by 50 tons in 27 years. Transport, on the other hand, produces 880 tons of CO2 equivalent (2017) and in the same 27 years has increased its production by 180 ton, which is roughly equivalent to emission from cattle in 2017.

The numbers are similar for the United States, however, GHG production has not decreased since 1990. Total GHG emissions in the USA in 2017 were 5700 tons of $\mathrm{CO} 2$ equivalent and, at 5400 tons of $\mathrm{CO} 2$ equivalent, the energy sector was the greatest contributor. Agriculture emitted 540 tons of $\mathrm{CO} 2$ equivalent, which represents $8.4 \%$ of the total production. Enteric fermentation by cattle was 175 tons. In contrast, from 19902017, fossil fuel combustion increased from 4740 tons to 4910 tons (170 tons), which is almost equivalent to all enteric fermentation. Although animal scientists should continue to search for ways to reduce GHG emissions, the facts prompt the question, where should we really focus our attention?

Editorial Committee Austral Journal of Veterinary Sciences

EU annual GHG inventory report May 2019.

Inventory of U.S. Greenhouse Gas Emissions and Sinks: 1990-2017. 